\title{
MITIGASI BENCANA PADA MASYARAKAT TRADISIONAL DALAM MENGHADAPI PERUBAHAN IKLIM DI KAMPUNG NAGA KECAMATAN SALAWU KABUPATEN TASIKMALAYA \\ (Disaster Mitigation on Traditional Community Against Climate Change in Kampong Naga Subdistrict Salawu Tasikmalaya District)
}

\author{
Indarti Komala Dewi ${ }^{\mathbf{1}^{*}}$ dan Yossa Istiadi ${ }^{2}$ \\ ${ }^{1)}$ Program Studi Perencanaan Wilayah dan Kota, Fakultas Teknik, Universitas Pakuan, \\ Jl. Pakuan, Bogor 16143. \\ ${ }^{2)}$ Prodi Pendidikan Kependudukan dan Lingkungan Hidup, Program Pascasarjana, \\ Universitas Pakuan, Jl. Pakuan, Bogor 16143. \\ *Penulis korespondensi. Tel: 0251-811007. Email: indartikade@gmail.com.
}

Diterima: 9 Juli 2015

Disetujui: 22 September 2015

\begin{abstract}
Abstrak
Fenomena pemanasan gobal yang diiringi dengan terjadinya perubahan iklim, merupakan ancaman nyata bagi masyarakat di masa kini dan yang akan datang. Indonesia merupakan salah satu negara yang rentan terkena dampak perubahan iklim. Kabupaten Tasikmalaya menduduki urutan kelima peringkat indeks rawan bencana di Indonesia. Kecamatan Salawu di Kabupaten Tasikmalaya rawan bencana. Kampung Naga adalah kampung yang masih memegang kuat budaya dan adat di Kecamatan Salawu. Tujuan penelitian adalah untuk menganalisis potensi bencana terkait perubahan iklim di Kampung Naga dan menganalisis kemampuan mitigasi bencana masyarakat Kampung Naga terhadap perubahan iklim. Penelitian ini menggunakan metoda analisis deskriptif kualitatif. Potensi bencana dianalisis secara kualitatif berdasarkan kondisi geomorfologi dan lokasi kampung. Kemampuan mitigasi bencana dianalisis secara kualitatif berdasarkan adat istiadat. Bahaya akibat perubahan iklim yang berpotensi menjadi bencana di Kampung Naga adalah tanah longsor dan banjir. Kemampuan mitigasi bencana masyarakat Kampung Naga terhadap perubahan iklim dipengaruhi kearifan tradisional yang tercermin dari konservasi hutan, bangunan, infrastruktur dan pola ruang kampung yang dapat mengurangi ancaman bencana tanah longsor dan banjir.
\end{abstract}

Kata kunci: banjir, bencana, mitigasi, perubahan iklim, tanah longsor, tradisional.

\begin{abstract}
The phenomenon of global warming which is accompanied by climate changed, is the real threat to the community in the present and future. Indonesia is one of the most vulnerable countries affected by climate change. Tasikmalaya is the district with rank of hazard indexes is $5^{\text {th }}$ in Indonesia. Sub district Salawu in Tasikmalaya district is a disaster-prone districts. One kampong in Salawu which still holds strong culture and customs is Kampung Naga. The aim of the study were analyzed potential disaster that related of climate change in Kampung Naga, and analyzed the the abilities of Kampung Naga community in mitigating disaster of climate change. The study used a qualitative descriptive analysis method. Potential disaster analyzed qualitatively based on condition of geomorphologi and location. Disaster mitigation capabilities were analyzed qualitatively from customs. Based on geomorphologi condition and location, hazards of climate change that could potentially be disastrous in Kampung Naga were landslide and floods. The abilities of Kampung Naga community in disaster mitigation of climate change, is affected by the traditional wisdom that was reflected from forest conservation, building, infrastructure and spatial patterns of kampong which could prevent landslide and flood.
\end{abstract}

Keywords: climate change, disaster, floods, landslide, mitigation, traditional.

\section{PENDAHULUAN}

Perubahan iklim merupakan ancaman terbesar bagi kehidupan umat manusia saat ini. Hal tersebut karena perubahan iklim yang terjadi saat ini berpotensi meningkatkan frekuensi kejadian ekstrim di berbagai wilayah di dunia (Anonim, 2014 ). Dampak perubahan iklim sangat kompleks karena terjadi pada berbagai sektor yang mencakup bebagai aspek kehidupan, antara lain kesehatan, pertanian, kehutanan, infrastrukur, transportasi, pariwisata, energi dan sosial. Potensi bencana terkait perubahan iklim menempati hampir $80 \%$ dari berbagai bencana alam yang ada di dunia (Sultonulhuda dkk., 2013). Potensi bencana tersebut antara lain banjir, kekeringan, angin puting beliung, erosi lahan, abrasi pantai, kebakaran hutan, wabah penyakit dan rawan pangan.

Berbagai potensi bencana alam terkait perubahan iklim dapat menimbulkan kerugian dalam 
bentuk kehilangan harta benda dan korban jiwa. Potensi kerugian yang ditimbulkan oleh bencana tersebut, dapat dikurangi melalui mitigasi. Mitigasi diartikan sebagai upaya mengurangi dan mencegah risiko kehilangan jiwa dan harta benda baik melalui pendekatan struktural maupun non-struktural (Nursa'ban dkk., 2010). Mitigasi struktural merupakan upaya pengurangan risiko bencana melalui pembangunan fisik serta rekayasa teknis bangunan tahan bencana, sedangkan mitigasi nonstruktural adalah upaya pengurangan risiko bencana yang bersifat non fisik seperti kebijakan, pemberdayaan masyarakat, penguatan institusi, kepedulian (Sugiharyanto dkk., 2014). Dalam mengurangi risiko bencana, mitigasi non struktural lebih berkelanjutan karena memberikan keamanan dalam jangka panjang.

Pengurangan risiko bencana melalui kearifan tradisional merupakan bentuk dari mitigasi non struktural. Kearifan tradisional adalah pengetahuan tradisional yang khas milik masyarakat atau budaya tertentu yang telah berkembang lama, dan merupakan hasil dari proses hubungan timbal-balik antara masyarakat dengan lingkungannya, menjadi acuan berperilaku, dipraktekkan dan diwariskan dari generasi ke generasi (Sartini, 2004; Permana dkk., 2011; Wibowo dkk., 2012). Kearifan tradisional sebagai pedoman, pengontrol, dan rambu-rambu berperilaku dalam kehidupan bermasyarakat mempunyai fungsi yang sangat penting dalam memelihara kelestarian sumberdaya alam dan lingkungan (Wibowo dkk., 2012). Kearifan tradisional antara lain mengajarkan perilaku manusia dalam berinteraksi dengan alam, melalui tabu, mitos dan ritual adat (Sartini, 2004; Wibowo dkk., 2012).

Indonesia yang merupakan negara kepulauan, sangat rentan terhadap dampak dari perubahan iklim. Di Indonesia bencana akibat perubahan iklim sebagian besar berupa bencana hidrometeorologis. Data BNPB 2011 menunjukkan bencana banjir, tanah longsor, dan banjir disertai tanah longsor mencapai 57\% dari total bencana yang terjadi di Indonesia. Berbagai kejadian bencana telah memberikan pengalaman empiris pada masyarakat Indonesia dalam hal menghadapi dan mengurangi risiko bencana. Berdasarkan penelitian terhadap masyarakat tradisional di beberapa daerah di Indonesia seperti masyarakat Baduy di Banten (Permana dkk., 2011; Suparmini, dkk., 2014) serta masyarakat Simeuleu, Nias dan Siberut (Meyers dan Watson, 2008) diketahui bahwa kearifan tradisional yang dimiliki masyarakat tersebut dapat mengurangi risiko bencana.

Kabupaten Tasikmalaya adalah salah satu dari 50 wilayah terentan terhadap perubahan iklim di
Indonesia (Anonim, 2014 ). Data indeks rawan bencana tahun 2013, menunjukkan bahwa Kabupaten Tasikmalaya menduduki urutan ke lima dari 496 kabupaten di Indonesia dengan kelas kerawanan tinggi terhadap bencana (Anonim, 2014 ). Data BPBD Kabupaten Tasikmalaya 2013, menunjukkan bahwa Kabupaten Tasikmalaya merupakan salah satu wilayah di Jawa Barat yang rawan gempa bumi dan tanah longsor. Selain tanah longsor, bencana banjir juga kerap terjadi di Kabupaten Tasikmalaya, terutama pada musim hujan. Menurut BPBD Kabupaten Tasikmalaya, terdapat 17 kecamatan di Kabupaten Tasikmalaya yang termasuk kawasan rawan bencana alam, salah satu kecamatan yang rawan bencana tersebut adalah Kecamatan Salawu. Kampung Naga yang terletak di Desa Neglasari, Kecamatan Salawu merupakan kampung yang rawan bencana alam. Kampung Naga berada di lembah sungai Ciwulan, diapit perbukitan dataran tinggi yang membujur dari barat ke timur, dilalui sesar dan berlokasi $<5 \mathrm{~km}$ dari pusat gempa. Kampung Naga adalah kampung tradisional yang masih memegang kuat budaya dan adat di Kecamatan Salawu. Walaupun daerahnya rawan bencana alam, tetapi Kampung Naga hingga saat ini tetap aman dari bencana alam. Berdasarkan hal tersebut, menarik untuk diamati tentang kemampuan yang dimiliki masyarakat Kampung Naga dalam memitigasi bencana. Dengan demikian tujuan penelitian adalah menganalisis potensi bencana terkait perubahan iklim di Kampung Naga dan menganalisis kemampuan mitigasi bencana masyarakat Kampung Naga terhadap perubahan iklim.

\section{METODE PENELITIAN}

\section{Waktu dan Lokasi}

Penelitian dilakukan dari bulan Maret-Oktober 2014. Lokasi penelitian adalah Kampung Naga. Secara geografis Kampung Naga terletak pada Koordinat $7^{\circ} 21$ '49,024” - 7²1'31,757” Lintang Selatan dan 10759'24,753” - 10759'44,252” Bujur Timur. Secara administratif Kampung Naga terletak di Kampung Nagara Tengah Desa Neglasari Kecamatan Salawu Kabupaten Tasikmalaya Provinsi Jawa Barat. Berdasarkan hasil analisis citra landsat (BING MAP 2010), wawancara dan observasi lapangan, luas Kampung Naga diperkirakan \pm 17,64 ha (Gambar 1).

\section{Prosedur Penelitian}

Penelitian ini menggunakan data primer berupa observasi dan wawancara. Pengambilan sampel dilakukan dengan dengan teknik tidak acak (non random). Responden ditentukan secara purposif. 


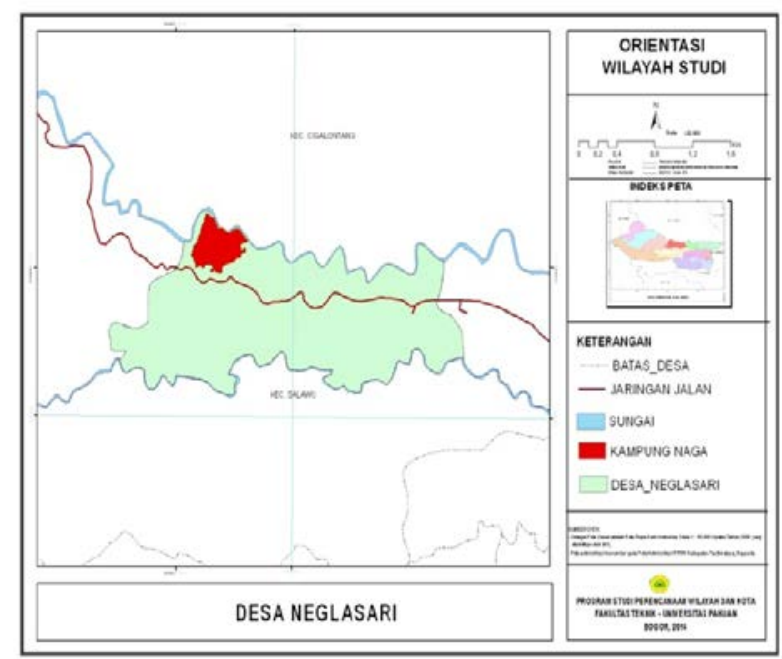

(a)

Gambar 1. Lokasi penelitian (a)

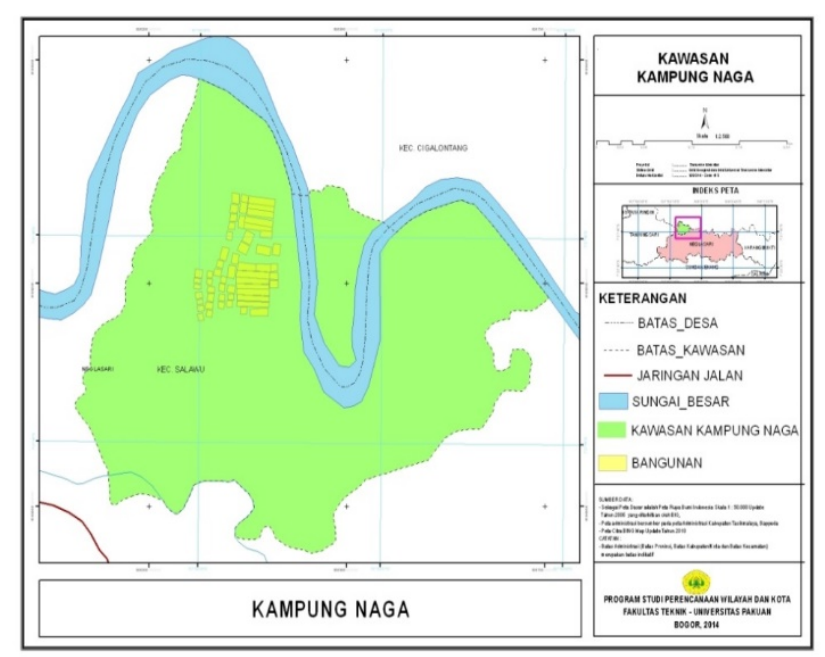

(b)

Untuk informan kunci respondennya adalah Kuncen dan Punduh, serta para pemandu wisata yang mengetahui adat-istiadat Kampung Naga. Pengambilan sampel masyarakat Kampung Naga dilakukan dengan teknik insidental. Wawancara dilakukan secara terstruktur menggunakan daftar pertanyaan dengan bentuk terbuka. Pertanyaan berkaitan dengan kondisi kampung secara umum, adat istiadat, kehidupan sosial, kehidupan ekonomi, pengaruh budaya dari luar Kampung Naga dan halhal lain terkait upaya mitigasi bencana. Data sekunder berupa dokumen, literatur dan peta. Sumber data sekunder adalah instansi, perpustakaan dan media elektronik.

Analisis menggunakan metoda kualitatif deskriptif. Potensi bencana akibat perubahan iklim di Kampung Naga dianalisis secara kualitatif menggunakan beberapa variabel yaitu posisi kampung Naga terhadap Sungai Ciwulan, potensi gerakan tanah dan sesar, kemiringan lereng, jenis tanah, dan rencana penggunaan lahan (RTRW Kabupaten Tasikmalaya 2011-2031). Kemampuan mitigasi bencana penduduk Kampung Naga dianalisis secara deskriptif kualitatif terhadap adat budaya dalam hal dalam menjaga hutan, membuat bangunan, infrastruktur dan penataan ruang kampung.

Selanjutnya dilakukan verifikasi terhadap hasil analisis menggunakan metoda triangulasi. Dalam hal ini hasil analisis terhadap dokumen diverifikasi oleh wawancara dan observasi, demikian pula hasil wawancara diverifikasi oleh data sekunder dan observasi

\section{HASIL DAN PEMBAHASAN}

\section{Potensi Bencana terkait Perubahan Iklim di Kampung Naga}

Di Kabupaten Tasikmalaya bagian utara terdapat sesar yang memanjang barat-timur. Sesar

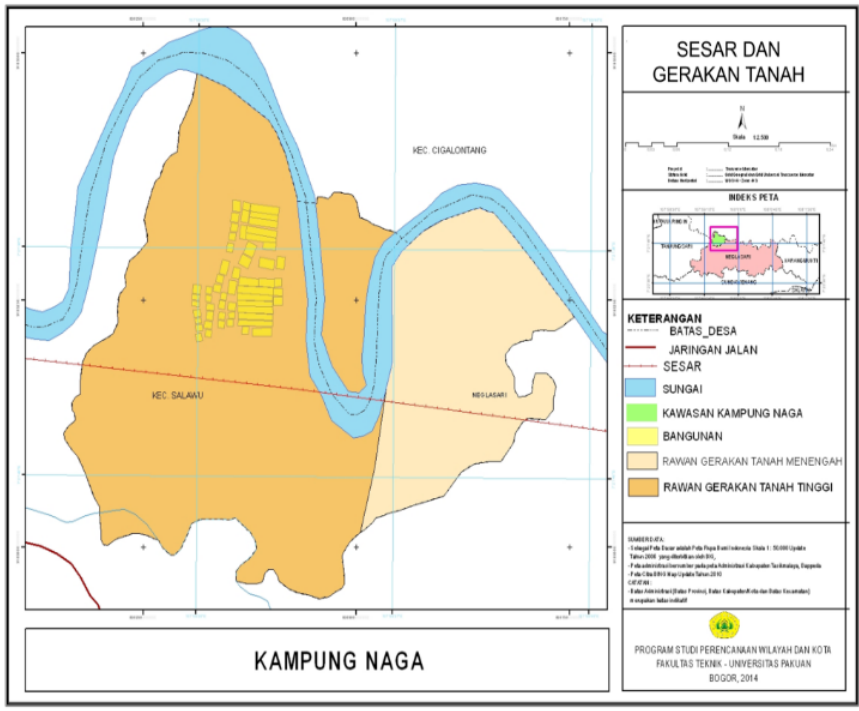

Gambar 2. Sesar dan potensi gerakan tanah di Kampung Naga.

tersebut melalui kawasan Kampung Naga. Berkaitan dengan sesar tersebut, data dari Bapeda Kabupaten Tasikmalaya, menyebutkan bahwa kawasan Kampung Naga masuk dalam zona gerakan tanah tinggi (Gambar 2). Dampak dari gerakan tanah yang bersinergi dengan perubahan iklim, berpotensi menghasilkan bencana longsor. Selain itu bencana longsor juga dapat disebabkan oleh kombinasi antara faktor antropogenik dan alam (Naryanto, 2011). Dalam hal ini, faktor antropogenik adalah aktivitas manusia dalam penggunaan lahan dan faktor alam adalah iklim (Nursa'ban dkk., 2010).

Kampung Naga terletak di lembah sungai Ciwulan, Posisi lahan di bagian barat Kampung Naga lebih tinggi dibandingkan dengan di bagian timur, dalam hal ini bagian timur berbatasan langsung dengan sungai Ciwulan. Masyarakat Sunda menyebut posisi kawasan seperti itu dengan istilah taneuh bahe ngetan yaitu kondisi lahan dengan 
kontur miring ke arah timur (Hermawan, 2014). Akibatnya bagian timur kampung rawan terkena banjir dari sungai Ciwulan. Dengan demikian berdasarkan kondisi geomorphologi, bahaya akibat perubahan iklim yang berpotensi menjadi bencana di Kampung Naga adalah longsor dan banjir.

\section{Potensi longsor}

Longsor dapat disebabkan oleh beberapa hal antara lain gerakan tanah, lereng yang curam, curah hujan, jenis tanah, pengelolaan lahan, dan beban dinamis dari lalulintas atau kegiatan pembangunan (Zakaria, 2010). Kampung Naga mempunyai potensi gerakan tanah tinggi dan dilalui sesar (Gambar 2). Kampung Naga mempunyai morfologi berbukitbukit dengan ketinggian antara $593-660 \mathrm{~m}$ dpl, dan kemiringan lereng antara 8-40\%. Perumahan berada pada ketinggian 609 - $624 \mathrm{~m}$ dpl, pada kemiringan lereng 15 -25\% (Gambar 3).

Walaupun di Kampung Naga curah hujan antara 13,6-20,7 mm/hari hujan termasuk kategori rendah, tetapi Kampung Naga mempunyai jenis tanah Ultisol (podsolik merah kuning). Tanah Ultisol umumnya peka terhadap erosi serta mempunyai pori aerasi dan indeks stabilitas rendah (Prasetyo dan Suriadikarta, 2006). Berdasarkan potensi gerakan tanah, kemiringan lereng, dan jenis tanah, maka potensi longsor di Kampung Naga cukup besar terutama di kawasan berbukit yang ada di bagian barat.

Peta tutupan lahan Kampung Naga dan sekitarnya menunjukkan bahwa saat ini hutan yang masih terpelihara berada di wilayah Kampung Naga, sedangkan tutupan lahan di daerah perbukitan di luar Kampung Naga adalah, kebun campuran, sawah dan perumahan. Pemanfaatan lahan sawah dan perumahan di daerah perbukitan dapat menjadi pemicu longsor. Pengamatan lapangan pada bulan Maret 2014, memperlihatkan di bukit dengan pemanfaatan lahan untuk kebun campuran terjadi longsor tebing dengan luas yang kecil. Berdasarkan hasil wawancara terhadap penduduk pada bulan Maret 2014, diperoleh informasi bahwa longsor memang kadang-kadang terjadi di lahan kebun campuran dan sawah.

Kampung Naga yang berada di lembah sungai dan dikelilingi tebing, berlokasi tidak jauh $( \pm 1 \mathrm{~km})$ dari Jalan raya Tasikmalaya - Garut. Getaran akibat lalu lintas juga dapat memicu longsor pada tebing yang di atasnya terdapat jalan raya. Dengan demikian berdasarkan jenis tanah, kemiringan lereng, tutupan lahan sekitar kampung, dan getaran dari jalan raya, maka longsor merupakan bahaya yang berpotensi mengancam Kampung Naga.

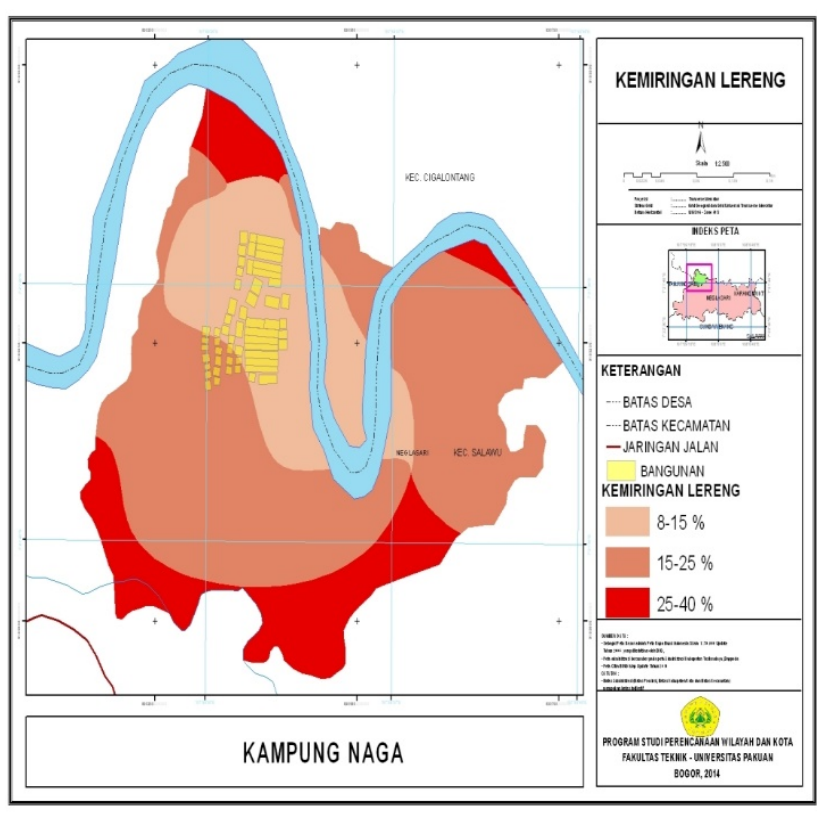

Gambar 3. Kemiringan lereng Kampung Naga.

\section{Potensi banjir}

Berdasarkan Rencana Tata Ruang Wilayah (RTRW) Kabupaten Tasikmalaya Tahun 20112031, Kampung Naga ditetapkan sebagai kawasan konservasi (kawasan cagar budaya) sedangkan wilayah sekitar Kampung Naga ditetapkan sebagai kawasan lahan basah/sawah. Oleh karena itu walaupun hutan di Kampung Naga tetap terjaga secara formal (hukum) dan non formal (adat), tetapi kebijakan tersebut dikhawatirkan akan berdampak. Hal tersebut karena hutan atau kebun campuran, kemampuan daya serap airnya lebih baik dibandingkan sawah, sehingga hutan atau kebun campuran dapat mengurangi bahaya banjir maupun longsor.

Jarak perumahan di Kampung Naga dari bibir sungai Ciwulan < $100 \mathrm{~m}$. Apabila menggunakan standar sempadan sungai (Keppres No 32/1990 tentang Pengelolaan Kawasan Lindung), sebagian dari perumahan di kampung Naga berada pada kawasan sempadan sungai. Ketinggian Kampung Naga dari muka air sungai antara 10-50 m. Aliran sungai Ciwulan menikung tajam di bagian selatan Kampung. Arus deras sungai Ciwulan telah mengikis sebagian bibir sungai di bagian selatan kampung. Untuk mengurangi abrasi yang disebabkan arus deras sungai Ciwulan tersebut, pemerintah daerah pada tahun 2009 memasang 2 buah talud dan pada 2013 menambah lagi 2 buah talud. Berdasarkan letak kampung terhadap sungai Ciwulan tersebut dan dibuatnya talud, maka potensi terkena banjir cukup besar apabila air sungai Ciwulan meluap. 


\section{Kemampuan Mitigasi Bencana Masyarakat Kampung Naga Terhadap Perubahan Iklim}

Berdasarkan hasil pembahasan tentang potensi bencana akibat perubahan iklim di Kampung Naga, disimpulkan terdapat dua bencana yang mengancam Kampung Naga yaitu longsor dan banjir. Kemampuan masyarakat Kampung Naga memitigasi bencana dipengaruhi oleh adat istiadat yang secara kuat dipegang teguh dalam menjalankan kehidupan. Prospek mitigasi bencana yang melembaga secara tradisi dipengaruhi oleh dinamika masyarakat. Pada masyarakat tradisional, dinamika masyarakat terproteksi oleh adat istiadat, dalam hal ini tradisi merupakan tali pengikat yang kuat dalam membangun tata tertib masyarakat (Ningrum, 2012). Pelestarian adat istiadat dan kearifan tradisional yang mampu memitigasi bencana dilakukan masyarakat melalui proses belajar tentang nilai-nilai hidup selaras dengan alam, dari sejak dini dalam lingkungan keluarga melalui keteladan orang tua, pembiasaan, dan ajakan. Di Kampung Naga masyarakat patuh melaksanakan aturan adat, sehingga dinamika masyarakat terkontrol oleh adat (Ningrum, 2012). Dalam hal ini peran pemimpin adat dalam mengontrol dinamika masyarakat tersebut sangat besar. Di Kampung Naga pemimpin adat atau ketua adat disebut Kuncen. Kuncen merupakan tokoh kunci sekaligus pemimpin adat dalam proses pewarisan dan pelestarian nilai-nilai kearifan tradisional. Peranan adat yang kuat dalam mengatur hubungan masyarakat dengan alam diduga berpengaruh terhadap kemampuan masyarakat dalam memitigasi bencana.

Penataan ruang kampung Naga yang dapat memitigasi bencana berpedoman pada konsep kosmologi Tri Tangtu di Bumi yang merupakan filosofi dasar masyarakat sunda (Rusmana, 2008). Konsep Tri Tangtu di Bumi, membagi dunia menjadi atas - tengah - bawah (Rusmana, 2008; Deny, 2008). Sejalan dengan hal tersebut masyarakat Kampung Naga pun membagi wilayahnya menjadi tiga, yaitu dunia atas (kawasan sakral) dunia tengah (kawasan netral) dan dunia bawah (kawasan buruk). Kawasan sakral/dunia atas direpresentasikan oleh hutan keramat yang berada di atas bukit di bagian barat kampung. Kawasan netral/dunia tengah direpresentasikan oleh perumahan, sawah dan kebun campuran. Dunia bawah direpresentasikan oleh hutan larangan di sebelah timur kampung di seberang sungai Ciwulan.

Hutan keramat merupakan tempat leluhur Kampung Naga dikuburkan. Tempat tersebut merupakan tempat sakral yang dihormati. Dari tempat sakral ini mengalir kebaikan. Hutan keramat diwasiatkan untuk dijaga dan tabu untuk dimasuki atau mengambil apapun dari dalamnya, dan hanya boleh dimasuki oleh ketua adat (kuncen) pada saat upacara adat. Pohon-pohon di hutan keramat tidak boleh ditebang. Hutan keramat berperan sebagai hutan lindung karena melindungi kawasan di bawahnya yaitu kawasan perumahan dan pertanian (kebun campuran dan sawah) dari bencana longsor dan banjir. Hutan keramat yang berada di atas bukit, meresapkan air hujan, sehingga air hujan tidak membanjiri kawasan di bawahnya. Dalam hal ini masyarakat Kampung Naga mengatakan "leuweung mah imah kai, kai mah imah cai" artinya hutan tempat pepohonan, dan pepohonan rumah air. Hal itu menunjukkan, bahwa masyarakat paham bahwa hutan dapat mengatur tata air, agar tidak banjir dimusim hujan dan kering dimusim kemarau. Dengan demikian, menjaga kelestarian hutan keramat merupakan bentuk mitigasi non struktural yang dilakukan masyarakat adat untuk mengurangi bencana longsor dan banjir yang sesuai dengan amanat adat untuk selalu hidup selaras dengan alam.

Kawasan netral/dunia tengah merupakan tempat masyarakat tinggal dan berkegiatan terdiri atas: perumahan, sawah dan kebun campuran. Mitigasi untuk mencegah longsor dilakukan dengan membuat lahan sawah dan kebun campuran berundak-undak mengikuti kontur. Demikian pula halnya dalam menata letak bangunan. Bangunan diletakan mengikuti kontur. Agar tidak mudah longsor, maka undakan tanah diberi batu dicampur tanah liat. Selain itu tebing yang curam di kebun campuran atau sawah ditanami pohon bambu atau aren untuk mencegah longsor. Hal tersebut adalah bentuk mitigasi struktural yang dilakukan masyarakat Kampung Naga yang berpedoman pada amanah untuk selalu menjaga keharmonisan dengan alam.

Bentuk mitigasi non struktural untuk mengurangi risiko bencana banjir adalah dengan menata ruang kampung dan perumahan sedemikian rupa, sehingga air dari tempat tinggi di bagian barat kampung dapat mengalir secara gravitasi ke sungai Ciwulan di bagian timur. Peletakan bangunan memanjang barat-timur mengikuti kontur dengan pola grid menghadap utara atau selatan. Pola peletakan rumah tersebut merupakan kearifan tradisional, karena lorong antar bangunan yang memanjang barat-timur selain digunakan sebagai jalur pergerakan juga sebagai saluran drainase. Tapak bangunan lebih tinggi $\pm 15 \mathrm{~cm}$ dari lorong yang berfungsi sebagai drainase tersebut. Dengan demikian apabila hujan, air dari atap jatuh ke lorong tersebut mengalir ke tempat yang rendah tanpa membasahi bagian bawah rumah. Setelah hujan reda, tidak ada air tergenang di kawasan perumahan semua air mengalir ke sungai Ciwulan di bagian timur. 
Tabel 1. Kemampuan mitigasi bencana tanah longsor dan banjir pada masyarakat Kampung Naga

\begin{tabular}{|c|c|c|}
\hline Komponen & Mitigasi bencana longsor dan banjir & Bentuk mitigasi bencana \\
\hline Hutan & $\begin{array}{l}\text { - Menjaga kondisi hutan keramat di bagian barat kampung tetap } \\
\text { lestari, melalui aturan adat (tabu untuk masuk dan mengambil } \\
\text { apapun). Hal tersebut menjaga tata air dan mencegah longsor. }\end{array}$ & Non struktural \\
\hline Bangunan/ rumah & $\begin{array}{l}\text { - Tapak bangunan lebih tinggi } \pm 15 \mathrm{~cm} \text { dari lorong yang } \\
\text { berfungsi sebagai drainase. Hal tersebut dapat mencegah air } \\
\text { masuk ke dalam rumah } \\
\text { - Bangunan/rumah diletakan sesuai kontur, dan diperkuat } \\
\text { dengan batu dan tanah liat untuk mencegah longsor. }\end{array}$ & Struktural \\
\hline Pola ruang kampung & $\begin{array}{l}\text { - Tata letak bangunan memanjang barat-timur mengikuti kontur } \\
\text { dengan pola grid menghadap utara atau selatan. Pola ruang } \\
\text { tersebut membentuk lorong yang berfungsi sebagai jalan dan } \\
\text { drainase }\end{array}$ & Non struktural \\
\hline & $\begin{array}{l}\text { - Sawah dan kebun dibuat berundak-undak. Undak diperkuat } \\
\text { dengan bambu atau aren untuk mencegah longsor } \\
\text { - Dibuat kolam yang memisahkan perumahan dengan sungai } \\
\text { untuk mencegah air sungai masuk ke perumahan pada saat } \\
\text { sungai meluap. }\end{array}$ & Struktural \\
\hline Infrastruktur & $\begin{array}{l}\text { - Lorong yang berfungsi sebagai jalan dan drainase tidak di } \\
\text { semen, memanjang barat-timur dan dari tempat tinggi ke } \\
\text { tempat rendah, sehingga air dapat meresap dan mengalir } \\
\text { dengan lancar. } \\
\text { - Jalan lingkungan terbuat dari material batu dan tanah, sehingga } \\
\text { air dapat meresap. }\end{array}$ & Struktural \\
\hline
\end{tabular}

Sumber: Hasil analisis.

Kawasan perumahan terdiri dari zona bersih dan zona kotor. Zona bersih adalah kawasan yang berisi rumah-rumah penduduk. Zona kotor terdapat di sekeliling zona bersih. Di zona kotor terdapat kolam ikan yang diatasnya dipakai untuk MCK, menumbuk padi, dan kandang ternak. Antara zona bersih dan zona kotor diberi pagar pembatas dari bambu. Zona kotor di bagian timur berbatasan langsung dengan sungai Ciwulan. Ketinggian zona kotor lebih rendah dari zona bersih. Zona kotor yang merupakan kolam, sekaligus menjadi pembatas antara perumahan dengan sungai Ciwulan. Air dari perumahan mengalir ke kolam sebelum mengalir ke sungai, demikian pula apabila sungai meluap airnya akan mengisi kolam-kolam tersebut, sebelum masuk ke perumahan. Hal tersebut merupakan salah satu bentuk kearifan tradisional mencegah banjir pada saat musim hujan. Selanjutnya kemampuan mitigasi bencana longsor dan banjir masyarakat Kampung Naga diperlihatkan pada Tabel 1.

\section{KESIMPULAN}

Potensi bencana akibat perubahan iklim yang mengancam Kampung Naga adalah longsor dan banjir. Masyarakat Kampung Naga mempunyai kearifan tradisional dalam memitigasi bencana longsor dan banjir tersebut. Kemampuan mitigasi bencana akibat perubahan iklim tersebut dipengaruhi oleh adat istiadat yang secara kuat dipegang teguh oleh masyarakat dalam menjalankan kehidupan. Kemampuan mitigasi bencana masyarakat Kampung Naga terlihat dari cara masyarakat mengkonservasi hutan, meletakan bangunan, membangun infrastruktur dan pola ruang. Seiring dengan perkembangan kawasan sekitar Kampung Naga, dikhawatirkan terjadi peningkatan bahaya longsor dan banjir. Oleh karena itu kemampuan mitigasi bencana berbasis kearifan tradisional tersebut harus didukung oleh kebijakan pemerintah . Kebijakan pemerintah dalam hal ini adalah yang terkait penataan ruang kawasan sekitar kampung Naga. Pemanfaatan ruang sekitar Kampung Naga perlu dijaga terutama kawasan di sekitar sempadan Sungai Ciwulan agar tidak berubah fungsi menjadi kawasan terbangun.

\section{UCAPAN TERIMAKASIH}

Ucapan terimakasih kami sampaikan pada Kopertis Wilayah IV Jawa Barat dan Banten, Makalah ini merupakan bagian dari penelitian yang dibiayai dana hibah penelitian dari DIPA Kopertis Wilayah IV Jawa Barat dan Banten sesuai dengan surat perjanjian Penugasan Pelaksanaan Program Penelitian Hibah Fundamental Multi Tahun, dengan No : 1091/K4/KM/2014 tanggal 5 Mei 2014. 


\section{DAFTAR PUSTAKA}

Anonim, 2014a . Rencana Aksi Nasional Adaptasi Perubahan Iklim (RAN API). Badan Perencanaan dan Pembangunan Nasional (BAPPENAS). Jakarta.

Anonim, 2014 ${ }^{\mathrm{b}}$. Indeks Rawan Bencana Indonesia, Direktorat Penanggulangan Risiko Bencana, Deputi Bidang Pencegahan dan Kesiapsiagaan, Badan Nasional Penanggulangan Bencana (BNPB). Jakarta.

Deny, M., 2008. Rumah Tradisional Sunda dalam Perspektif Teori Paradoks (Sundanese Traditional House in Paradox Theory Perspective). Jurnal Ambiance, 1(2):1-19.

Meyers K., dan Watson, P., 2008. Simeulue, Nias, dan Siberut, Indonesia Dongeng, Ritual, dan Arsitektur di Kawasan Sabuk Gunung Api, dalam Kearifan Tradisional dalam Pengurangan Risiko Bencana:Praktik-praktik yang Baik dan Pelajaran yang Dapat Dipetik dari Pengalaman-pengalaman di Kawasan Asia-Pasifik. Rajib Shaw, Noralene Uy, dan Jennifer Baumwoll (editor), International Strategy for Disaster Reduction (ISDR) United Nation, pp.17-22.

Naryanto, H.S., 2011. Analisis Risiko Bencana Tanah Longsor di Kabupaten Karang anyar, Provinsi Jawa Tengah. Jurnal Penanggulangan Bencana, 2(1):21-32.

Ningrum, E., 2012. Dinamika Masyarakat Adat Tradisional Kampung Naga Di Kabupaten Tasikmalaya. Jurnal Mimbar, 28(1):47-54.

Nursa'ban, Sugiharyanto, dan Khotimah, 2010. Pengukuran Kerentanan Longsor Lahan Sebagai Upaya Mitigasi Bencana Di Perbukitan Menoreh. Jurnal Penelitian Saintek, 15(2):42-52.

Permana, R.C.E., Nasution, I.P., dan Gunawijaya, J., 2011. Kearifan tradisional Tentang Mitigasi
Bencana Pada Masyarakat Baduy. Jurnal Makara, Sosial Humaniora, 15(1):67-76.

Prasetyo, B.H., dan Suriadikarta, D.A., 2006. Karakteristik, Potensi, Dan Teknologi Pengelolaan Tanah Ultisol Untuk Pengembangan Pertanian Lahan Kering Di Indonesia. Jurnal Litbang Pertanian, 25(2):39-46.

Rusmana, T., 2008. Kidung Jaka Bandung. Jurnal Resital, 9(2):102-111.

Sartini, 2004. Menggali Kearifan Lokal Nusantara Sebuah Kajian Filsafati. Jurnal Filsafat, 37(2):111-120.

Sultonulhuda, Herdiansyah, H., dan Chrisandini, 2013. Panduan Pelatihan Adaptasi Perubahan Iklim Dan Pengurangan Risiko Bencana "Mengintegrasikan Kemampuan Adaptif Masyarakat Dalam Adaptasi Perubahan Iklim Dan Pengurangan Risiko Bencana“. Dewan Nasional Perubahan Iklim, Jakarta.

Sugiharyanto, Wulandari, T., dan Wibowo, S., 2014. Persepsi Mahasiswa Pendidikan IPS Terhadap Mitigasi Bencana Gempa Bumi. JIPSINDO, 2(1):164-182.

Suparmini, Setyawati, S., dan Sumunar, D.R.S. 2014. Mitigasi Bencana Berbasis Kearifan Lokal Masyarakat Baduy. Jurnal Penelitian Humaniora, 19(1):47-64.

Wibowo, H.A., Wasino, dan Setyowati, D.L., 2012. Kearifan Lokal dalam Menjaga Lingkungan Hidup (Studi Kasus Masyarakat di Desa Colo Kecamatan Dawe Kabupaten Kudus). Journal of Educational Social Studies 1(1):25-30.

Zakaria, Z., 2010. Model Starlet, Suatu Usulan untuk Mitigasi Bencana Longsor dengan Pendekatan Genetika Wilayah (Studi Kasus: Longsoran Citatah, Padalarang, Jawa). Jurnal Geologi Indonesia, 5(2):93-112. 